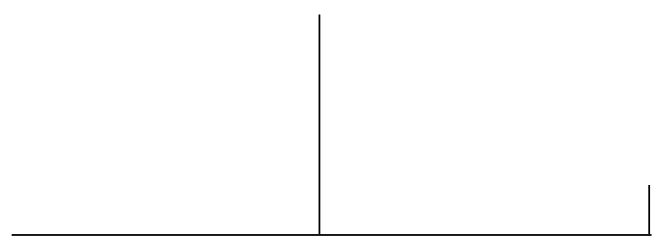

Rev. Latinoam. Psicopat. Fund., São Paulo, 16(1), 157-159, mar. 2013

Dicionário histórico de instituições de Psicologia no Brasil.

Ana Maria Jacó-Vilela (Org.)

Rio de Janeiro: Conselho Federal de Psicologia, 2011, 546 págs.

\title{
Histórico das Instituições de Psicologia no Brasil de A a Z
}

Ana Maria Galdini Raimundo Oda

Entusiasta dos dicionários desde a infância, o escritor francês Anatole France (1844-1924) disse que o dicionário é "o universo em ordem alfabética", o livro dos livros, onde estariam em germe todos os demais (a frase original, escrita para prefaciar um dicionário, hoje é replicada em dicionários de citações por outros admiradores de dicionários). Já os sentimentos do argentino Julio Cortázar (1914-1984) pelos vocabulários eram bem outros; no romance Rayuela (em português, $O$ jogo da amarelinha), ele substitui sistematicamente a palavra 'dicionário' por 'cemitério' (assim, alguém "consulta o cemitério"), ironizando o espírito conservador que costuma governar os léxicos. Na verdade, parece que cada um deles preferia destacar certas qualidades inerentes aos dicionários: a fascinante possibilidade de conhecimento que prometem ou a cristalização semântica que ameaçam.

Muito além do vernáculo, tudo é dicionarizável. Dicionarizar vem sendo um recurso usado em várias áreas 
do conhecimento como meio de catalogar ordenadamente um grande volume de informação sobre determinado assunto, constituindo dicionários temáticos, como o que aqui resenhamos. O Dicionário histórico de instituições de psicologia no Brasil, editado em 2011, é resultado de um significativo esforço coletivo de pesquisa, realizado sob a coordenação geral de Ana Maria Jacó-Vilela, da Universidade do Estado do Rio de Janeiro (UERJ). As investigações se deram entre os anos de 2006 e 2009 e o projeto congregou mais de duas centenas e meia de pesquisadores de três instituições, a UERJ, a Universidade Federal de Minas Gerais (UFMG) e a Pontifícia Universidade Católica de São Paulo (PUC-SP), contando também com a participação de pesquisadores do Grupo de Trabalho em História da Psicologia da Associação Nacional de Pesquisa e Pós-Graduação em Psicologia (ANPEPP) e com o apoio do Conselho Federal de Psicologia (CFP).

No caso, o termo "instituições" refere-se a estabelecimentos, associações e organizações (públicos ou privados) de pesquisa e formação em psicologia e de prestação de serviços psicológicos, incluindo ainda instituições relacionadas historicamente à extensa área "psi”" (instituições médicas, psiquiátricas e de educação, entre outras), tendo como limite temporal o ano de 1980, como data de fundação da entidade, e abrangendo todo o território nacional.

O livro é bem editado e de consulta fácil; os 264 verbetes estão em ordem alfabética, sendo cada entrada feita pelo nome completo da instituição (o atual ou o último), seguido pela data de criação e (se for o caso) a de dissolução. As denominações anteriores também são referidas, por exemplo, na entrada Hospital Nacional de Psicopatas (1927-1943), temos a seguir registrados os nomes de Hospital Nacional de Alienados (1911-1927); Hospício Nacional de Alienados (1890-1911) e Hospício de Pedro II (1852-1890). Os verbetes têm referências bibliográficas. Muito úteis aos pesquisadores são o Índice Onomástico (de personagens citados no Dicionário) e o Índice Remissivo de Instituições, que são listadas com seus nomes atuais e, quando pertinente, com os nomes antigos; ali também constam todas as instituições citadas no corpo dos verbetes, o que sem dúvida pode ser um excelente recurso para traçar conexões interinstitucionais. Ainda sobre o Índice Onomástico, recebem marcação os verbetes que constam também no Dicionário biográfico da Psicologia no Brasil - pioneiros (organizado por Regina Helena de Freitas Campos, Imago, 2001), facilitando a intersecção entre ambos os dicionários.

O Dicionário foi escrito por 261 colaboradores e, como aponta a sua coordenadora geral na Introdução, há evidentes diferenças nas estratégias de pesquisa usadas, bem como na experiência dos autores em pesquisa e, especificamente, em investigação histórica. A recomendação aos autores foi a de usar "redação em linguagem direta, na afirmativa, sem adjetivações", diz ainda a coordenadora. Como constatamos na apreciação geral do Dicionário e na leitu- 
ra de uma amostra dos verbetes, a maioria deles segue efetivamente tais recomendações, tem texto conciso e sóbrio e referências bibliográficas essenciais, dando uma visão geral da instituição e podendo ser também um bom ponto de partida para pesquisas adicionais. Alguns poucos verbetes (desta amostra que lemos) fogem deste padrão, estendendo-se em afirmações de caráter excessivamente ideologizado, opinativo. Porém, como indica a professora Ana Maria Jacó-Vilela, as diversas maneiras como os autores se expressam são também indicativas do estágio de desenvolvimento da pesquisa em história da psicologia no Brasil e, acrescentamos, não há nada que a leitura crítica não possa superar.

Seguindo o louvável espírito de democratização do conhecimento que moveu a feitura do Dicionário histórico, o livro em formato eletrônico está disponível no site da Biblioteca Virtual em Saúde (BVS) - Psicologia (em 'livros eletrônicos de acesso aberto': <http://newpsi.bvs-psi.org.br/ebooks2010/pt/acervo files/DicionarioHistorico.pdf $>$ ).

De acordo com a organizadora, planeja-se ainda uma versão virtual do $D i$ cionário, que poderá receber acréscimos e alterações no texto e a inserção de imagens, o que certamente ensejará a ampliação e o aprimoramento deste grande trabalho. Em suma, o Dicionário histórico de instituições de psicologia no Brasil cumpre sua função de obra de referência, apresentando, mais do que respostas completas, novas fontes de indagações, à espera dos leitores.

\section{Ana Maria Galdini Raimundo Oda}

Psiquiatra; Doutora em ciências médicas; Professora do Departamento de Medicina da Universidade Federal de São Carlos - UFSCar (São Carlos, SP, Br); Pesquisadora da área de história da psicopatologia e da psiquiatria; Editora associada da seção História da Psiquiatria da Revista Latinoamericana de Psicopatologia Fundamental (São Paulo, SP, Br), desde 2004.

Caminho 03, 104B - Condomínio Bosques de Notre Dame

Distrito de Sousas

13104-902 Campinas, SP, Br

e-mail: anaoda@ufscar.br 